\title{
Multiple variations of superficial and deep veins in the neck region of a cadaver: a case report
}

\author{
Nilgün Tuncel Çini (D), Nazan Güner Sak (D), Senem Turan Özdemir (D), İlknur Arı (D) \\ Department of Anatomy, School of Medicine, Bursa Uhudă̆ University, Bursa, Turkey
}

\begin{abstract}
Multiple variations on the right side of the neck of a 65-year-old male cadaver were observed during a routine dissection. The cadaver had no sign of facial trauma or previous surgery. The facial vein had a communicating branch with the internal jugular vein and distally drained into the jugulo-subclavian confluence via a common trunk with external jugular vein. Other superficial veins of the neck drained into the brachiocephalic vein separately. On the contrary, no anatomical variation was observed on the left side. Even if the variations of the head and neck are common, more than one variation in a single cadaver unilaterally is remarkable. We suggest that it is important for surgeons to examine the patients with ultrasound before any clinical interventions on the neck to determine the possible variations beforehand.
\end{abstract}

Keywords: external jugular vein; internal jugular vein; neck; retromandibular vein; variation

Anatomy 2020;14(2):150-155 (2020 Turkish Society of Anatomy and Clinical Anatomy (TSACA)

\section{Introduction}

The superficial vessels of the head and neck region have variable course and relationships. Moreover, they have variable connections with each other and variable drainage patterns. ${ }^{[1,2]}$ The information regarding veins of the head and neck depend on commonly observed patterns and generalized definitions. ${ }^{[2,3]}$

The main veins of the neck are the external jugular vein (EJV), the internal jugular vein (IJV) and the anterior jugular vein $(\mathrm{AJV})$. The retromandibular vein $(\mathrm{RV})$ is formed by union of the superficial temporal vein (STV) and the maxillary vein (MV) within the parotid salivary gland and in here it is divided into the anterior and posterior roots. The anterior root combines with the facial vein (FV) to form the common facial vein (CVF) which drains into the IJV, while the posterior root combines with the posterior auricular vein $(\mathrm{PAV})$ to form the $\mathrm{EJV} \cdot{ }^{[4]}$ The EJV starts at the level of mandibular angle, runs vertically over the sternocleidomastoid muscle (SCM) and opens into the subclavian vein (SCV) or to venous angle approximately 2 $\mathrm{cm}$ above the clavicle. The transvers cervical vein (TCV), the suprascapular vein (SSV), dorsal scapular vein (DSV), the AJV and the parotid gland vein (PGV) drain into the EJV in the vicinity of the SCV. The IJV starts as a continuation of sigmoid sinus, collects venous blood from the brain, and connects with the SCV behind the sternoclavicular joint to form the brachiocephalic vein (BCV). A branch from the facial vein and the retromandibular vein just below the angle of the mandible joins to the IJV vertically in the neck region. The other veins leading up to this vein are superior thyroid vein, lingual vein $(\mathrm{LV})$, middle thyroid vein, superior laryngeal vein, occipital vein, pharyngeal vein and common facial vein. The $\mathrm{AJV}$ is another superficial vein that extends inferiorly from the submental region to the lower part of the neck with a highly variable course. It emerges from the confluence the superficial submental veins (SMV) and drains into the EJV. Another vein

This case was a poster presentation at Uludă̆ Anatomy Winter Days, February 26-28, 2017, Bursa, Turkey 
of the neck is the vertebral vein (VV), which is formed by joining the branches of the internal vertebral venous plexus which is located in the vertebral canal, at the level of suboccipital triangle, opens to the $\mathrm{BCV}$ at the root of the neck from the posterior part. ${ }^{[4-6]}$

In this report, we present a case with multiple variations on the right side of the neck of a 65 -year-old male cadaver and review the localization, course, topographic relationships and the drainage patterns of the neck veins.

\section{Case Report}

During the routine dissection carried out in the Anatomy laboratory in Bursa Uludağ University Faculty of Medicine, multiple variations were observed on the right side of the neck region of a 65 -year-old male cadaver. The past medical history of the cadaver revealed no history of facial trauma or operation at the head and neck region. We observed that the STV, the MV and the PAV converged in the parotid gland and continued as the EJV on the SCM. In addition to this, the PGV drained into the MV and the LV drained to the EJV (Figure 1). In the second variation of the case, the $\mathrm{AJV}$ and the SMV were drained into the FV. The FV was connected to the middle part of the IJV with a thick root and distally drained into the EJV. The omohyoid muscle was passing through a communicating vein. Finally, the EJV drained into the jugulo-subclavian venous confluence. In addition to these variations, a communicating vein was observed between the SMV and the AJV (Figure 2). In the third variation of the case, anteriorly the common trunk of the EJV and the FV, SCV, the $\mathrm{IJV}$, and posteriorly the SSV combined to form the jugulo-subclavian confluence (Figure 3). The common trunk of the TCV and the DSV drained into the posterior part of the common trunk of the EJV and the FV. In addition, there was a connection between the DSV-TCV trunk and the EJV (Figure 4). The VV drained into the BCV on the posterior part as usual. Although there was more than one variation on the right side, no anatomical variation was observed on the left side. These variations belonged to a donation cadaver and the study was carried out according to the Helsinki protocol.

\section{Discussion}

Variations of the veins in the head and neck are common. ${ }^{[5-8]}$ There are so many case reports in the literature in which the RMV continues as the EJV without separating the anterior and posterior roots. Contrary to the classical knowledge, Olabu et al. ${ }^{[5]}$ reported that the RMV continued as the EJV in only $6.6 \%$ of 53 cadavers they studied. A FV drained into the EJV in $8.8 \%$ and the EJV which drained into the junction between IJV and subclavian vein in $2.2 \%$ of their cases. In the present case, we observed that EJV drained into the jugulo-subclavian confluence that was formed by union of the SCV,
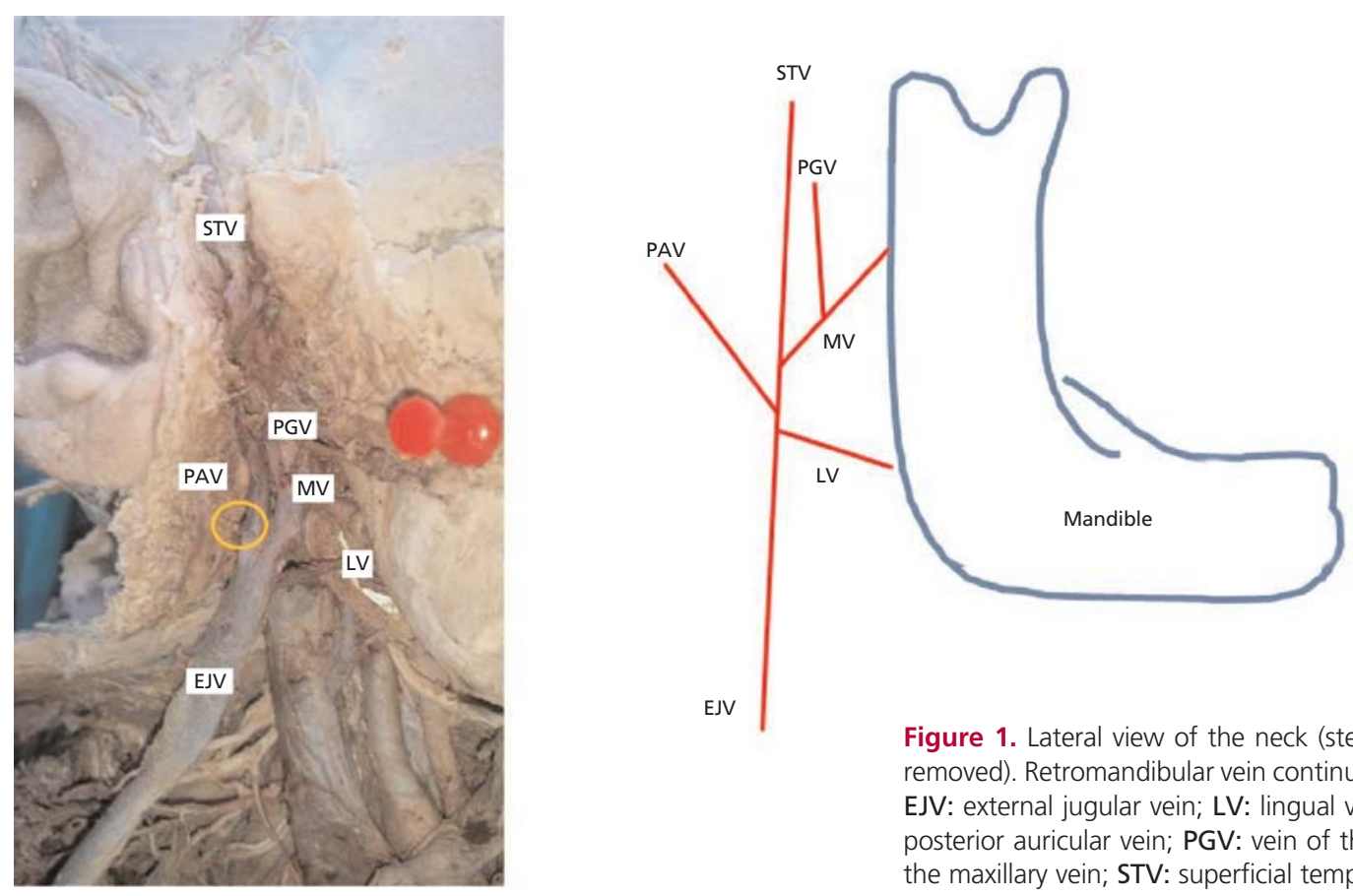

Figure 1. Lateral view of the neck (sternocleidomastoid muscle was removed). Retromandibular vein continues as the external jugular vein. EJV: external jugular vein; LV: lingual vein; MV: maxillary vein; PAV: posterior auricular vein; PGV: vein of the parotid gland draining into the maxillary vein; STV: superficial temporal vein. 


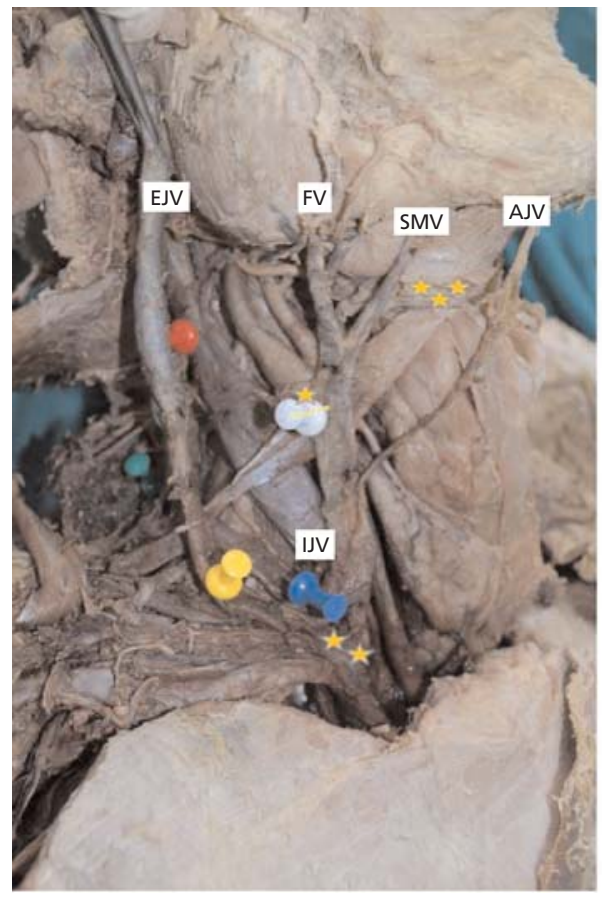

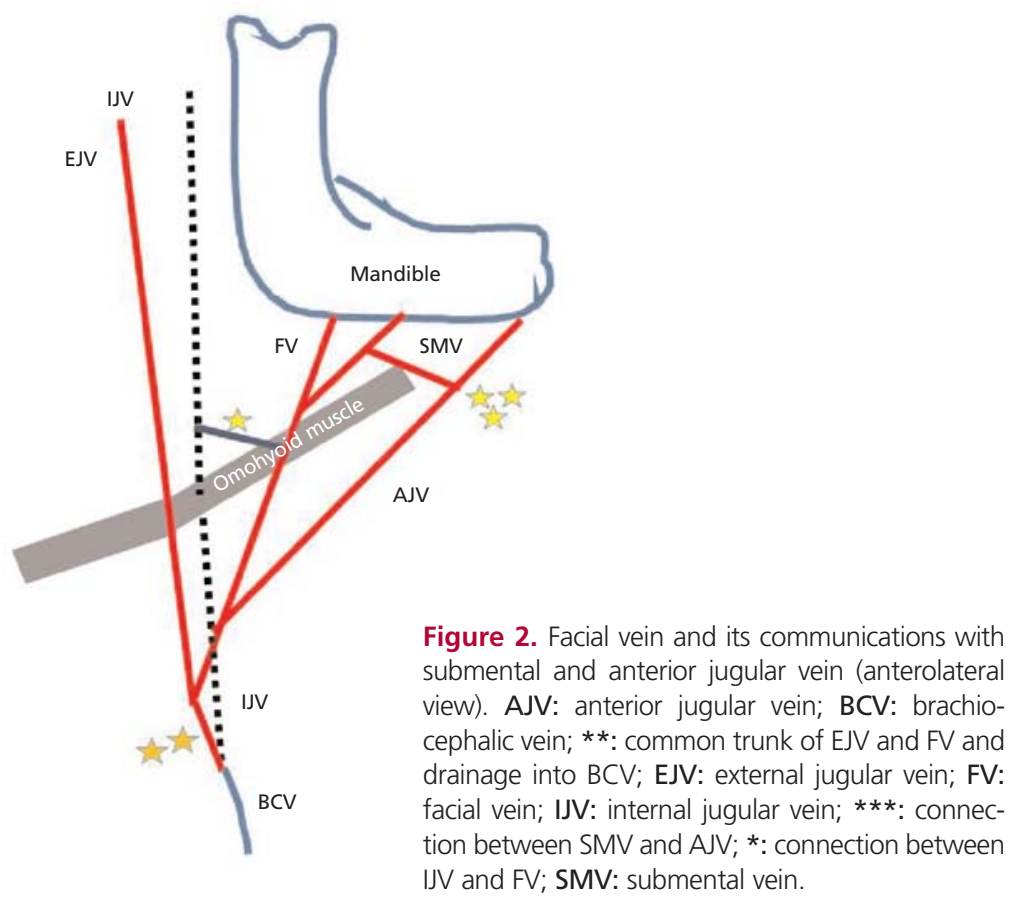

IJV, SSV, TCV and the common trunk of the AJV. Pai et al. ${ }^{[9]}$ showed that on the right side of one cadaver out of 52 cases, the RMV continued as the EJV by combining the $\mathrm{FV}$ at a different level and without formation of any roots. In the present case, we observed that the RMV also took the LV at the corner of the mandible, continued as the EJV without segregating from its anterior and posterior roots, and the FV took the SMV and the AJV and drained into the jugulo-subclavian junction approximately $2 \mathrm{~cm}$ above the clavicle.

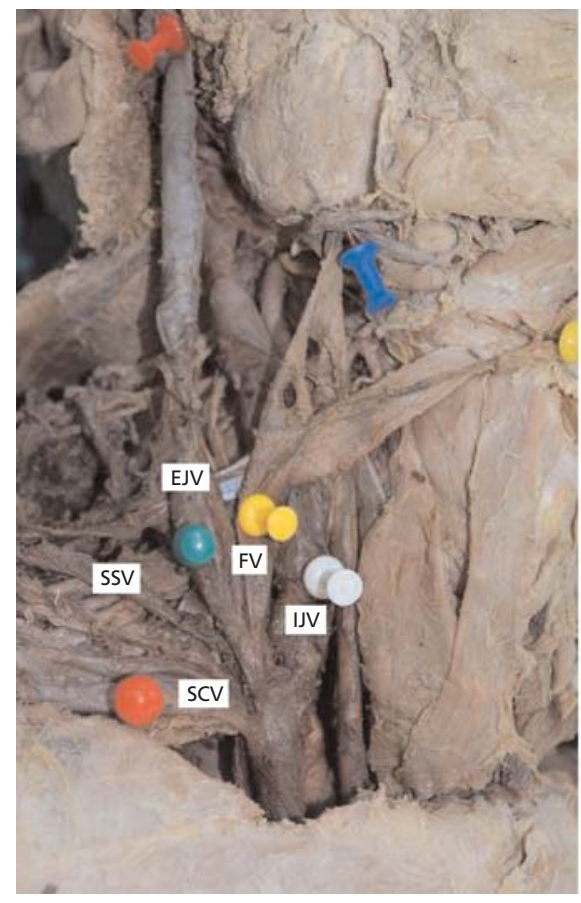

Anatomy • Volume 14 / Issue 2 / August 2020

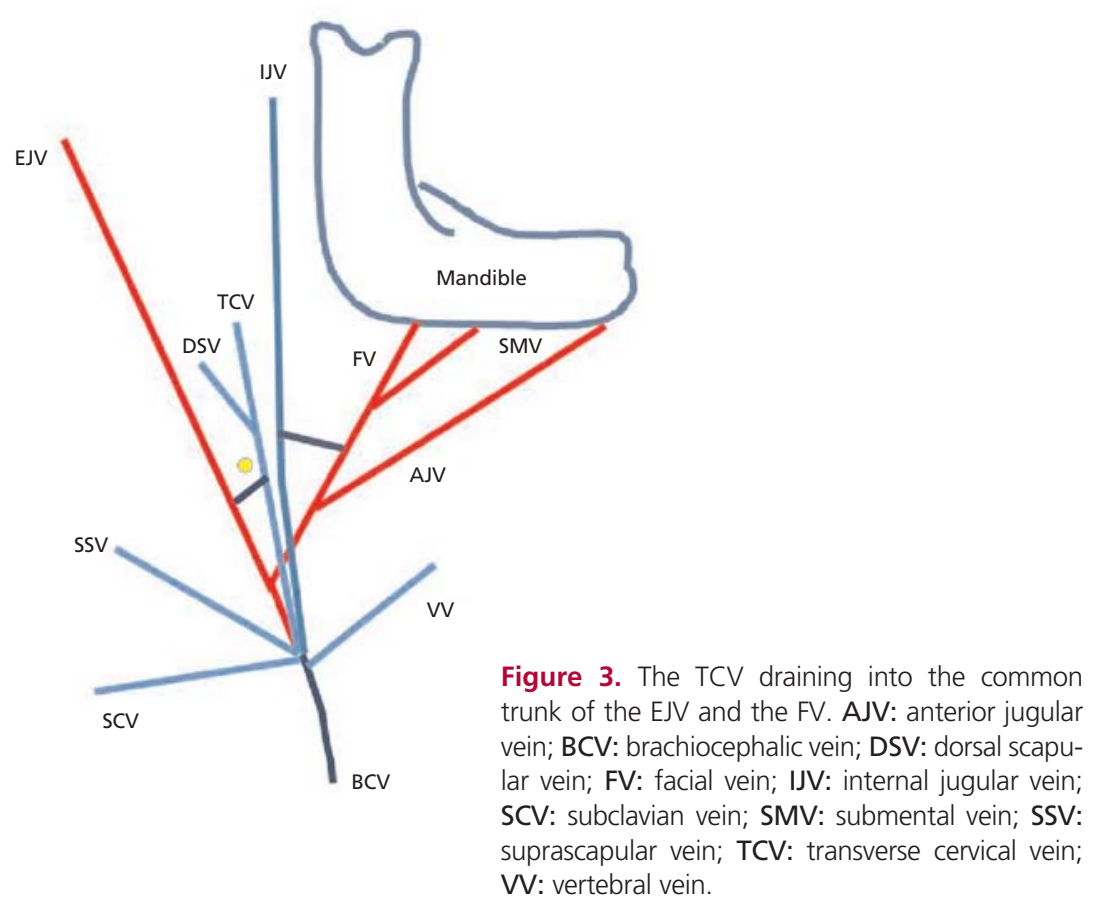
V: vertebral vein

Figure 3. The TCV draining into the common Figur vein; BCV: brachiocephalic vein; DSV: dorsal scapuvein; FV: facial vein; IJV: internal jugular vein; 


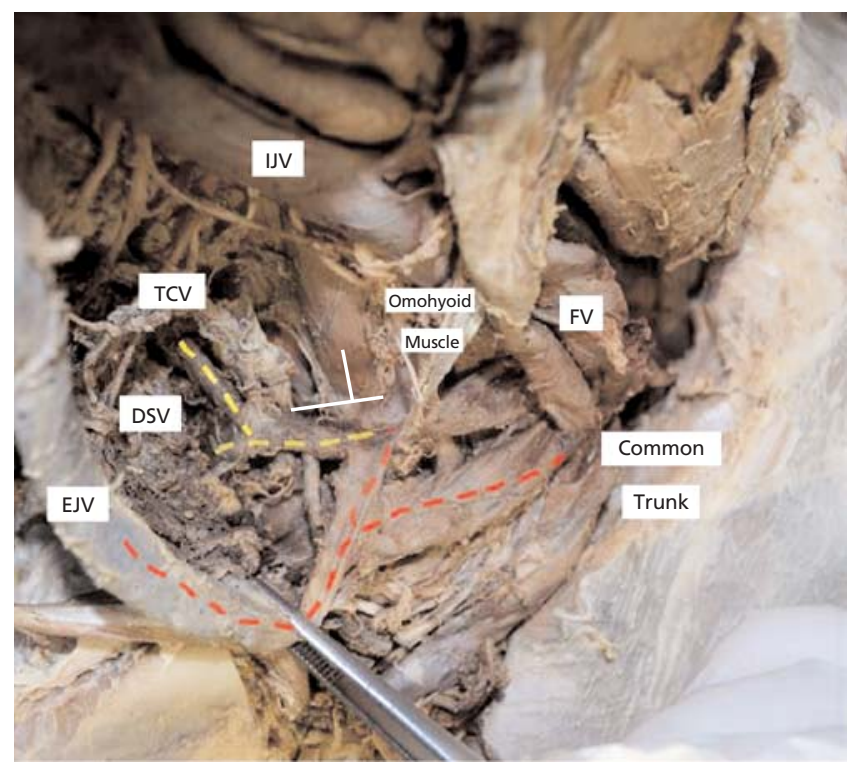

Figure 4. Jugulo-subclavian venous confluence (anterolateral view). Junction between the common trunk the TCV-DSV and the EJV. AJV: anterior jugular vein; BCV: brachiocephalic vein; DSV: dorsal scapular vein; FV: facial vein; IJV: internal jugular vein; SCV: subclavian vein; SSV: suprascapular vein; TCV: transverse cervical vein.

In a study carried out with 40 cadavers by Choudhary et al. $^{[10]}$ the $\mathrm{FV}$ drained into the EJV in 4 cadavers (5\%). Three of these drained into the distal of the SCV and the remaining one drained into the IJV. In the present case, we observed a communicating vein between the AJV and the SMV. Communicating veins may compensate the drainage of veins which are inadequate in size or width as a result of developmental disorders in the region and these veins are usually branches of the common facial vein. ${ }^{[1]}$

Panagouli et al. ${ }^{[2]}$ reported that the $\mathrm{CV}$, the TCV, the $\mathrm{EJV}$, the AJV, the IJV and the VV opened to the junction in a clockwise direction on the right side of the neck during cadaver dissection. In our case, it was again clockwise; anteriorly, the common trunk of the EJV and the $\mathrm{FV}, \mathrm{SCV}$, the IJV, and posteriorly the SSV combined to form the jugulo-subclavian confluence. The TCV drained into the posterior part of the common trunk of the EJV and the FV.

Deslaugiers et al. ${ }^{[12]}$ reported that the TCV drained into the $\mathrm{EJV}$ in $88 \%$, the SSV drained into the EJV in $47 \%$, the AJV drained into the EJV in $46 \%$ of their cases. They also found that the EJV drained into the jugulo-subclavian confluence in 60\%. Haas and Weiglein $^{[13]}$ reported that the TCV drainage into the EJV in $80 \%$, the SCV in $12 \%$ or both into the EJV and $\mathrm{SCV}$ in $8 \%$. In the present case, the TCV and the DSV drained into the common trunk of the EJV and FV. In addition, there was a connection between the common trunk and the EJV. Tellez-Hernandez et al. ${ }^{[14]}$ observed a common trunk of the TSV and the TCV in a routine dissection and this trunk drained into the EJV. The SSV could be absent or duplicated ,but its drainage generally was to the EJV. ${ }^{[15,16]}$ In the present case, its drainage was into the jugulo-subclavian venous confluence.

Gupta et al. ${ }^{[17]}$ made a classification and defined some types and subtypes for the RJV and the FV. Accordingly, the tuning-fork-shaped pattern composed of a common trunk of the FV and the EJV which drained into the subclavian vein $(12.5 \%)$. Krmpotic-Nemanic et al. ${ }^{[18]}$ made a classification and defined eight different patterns of the veins of this region. Our case is not completely similar with these different patterns. Howeveri in the fifth pattern, they claimed that undivided RMV and the FV came together and drained into the subclavian vein. In the present case, the undivided RMV and FV formed a common trunk and drained into the jugulo-subclavian venous confluence. Additionally, the FV had connection with the IJV.

Uncertainties that occur in the development of the vascular system during the embryological period can sometimes lead to anomalies that manifest with clinical aspects. ${ }^{[10]}$ The veins of the neck region develop after the development of the skull is completed. Two main venous vessels are seen at the $5 \mathrm{~mm}$ stage of the embryo. One of these veins is the ventral pharyngeal vein (VPV) which drains the mandibular and hyoid venous arches and finally drains into the common cardinal vein. The second major vessel is the primitive maxillary vein (PMV) which is located on the superolateral aspect of the VPV. At the $10 \mathrm{~mm}$ stage of the developing embryo, the drainage of the VPV is directed towards the cranial part of the precardinal vein, which later becomes the IJV. The development pf VPV continues and begins to receive branches from the face and tongue. After this, the VPV is named the linguofacial vein (LFV). On the other hand, the PMV forms the anterior facial vein (AFV) by anastomosing with the LFV. ${ }^{[19,20]}$

The RMV, which drains temporal region at the $18 \mathrm{~mm}$ embryo, forms a common root with the LFV and is named as common facial vein. It drains into the precardinal vein. At the $22 \mathrm{~mm}$ embryo, the jugulocephalic vein around the clavicle begins to develop annularly in relation to the caudal part of the precardinal vein and the EJV occurs as a secondary branch of the cephalic vein. Deep segments of the jugulocephalic vein forms the SCV. At the $40 \mathrm{~mm}$ embryo, the EJV is connected to the anterior part of the $\mathrm{AFV}$, the posterior part of the RMV and the precardinal vein. The anterior connection retracts to form the anteri- 
or root of the RMV and drain into the IJV via the CFV. The PAV opens to the posterior connection and forms the posterior root of the RMV and drains into the $S C V \cdot{ }^{[2,19]}$ As a result of selective expression or arrest during development in the embryo, abnormal or extra connections between the vessels may occur and cause different images of venous drainage of the region. ${ }^{[6]}$ The connections between the vessels usually occur at the $40 \mathrm{~mm}$ stage and sometimes occur early at the $22 \mathrm{~mm}$ stage, this situation causes the vessel variations. Ineffective development of the cephalic part of the EJV results in extra connections between the CFV and the EJV. As a result of degeneration of this cephalic fragment, no posterior connection between the EJV and the RMV is formed. Thus, undivided RMV formation is observed and the PAV is opened here. This embryological condition describes the RMV model that continues without division by taking the PAV ${ }^{[19]}$ Regression of the pre-connection between EJV and LFV causes the FV to drain directly to RMV (EJV). ${ }^{[21]}$

Variations of superficial veins on the neck region are of great importance for radiologists, anatomists and surgeons. Ultrasound-guided venipuncture is suggested in cases of variations in the superficial veins. ${ }^{[2]}$ Superficially located $\mathrm{EJV}$ is a point of interest in invasive procedures directed to the central venous system, parenteral feeding or maxillo-facial surgery. On the other hand, in the subclavian vein thrombosis, bypass between the cephalic vein and the external jugular vein is important for the prevention of arteriovenous fistulas for hemodialysis. ${ }^{[10]}$ Compared with large veins such as subclavian or femoral veins which have high risks in surgical procedures, the IJV and the EJV are easily accessible from the outside making them suitable for venous catheterization. In order to prevent complications such as carotid tears, occult bleeding, pneumothorax or emphysema during catheterization, it is important to know the variations of these vessel in advance. $^{[1,23]}$ The CFV is an important vein for venous monitoring and is used in ventriculojugular shunts for hydrocephalus. ${ }^{[2]]}$ The CFV and the EJV can be used for carotid endarterectomy. ${ }^{[2]}$ Thus, it is important to know the possible variations related with these veins.

\section{Conclusion}

In conclusion, head and neck veins subject to a wide range of variation. The present case is remarkable since multiple variations were present in a single cadaver unilaterally. We suggest visualization of all possible vascular variations with ultrasound before any interventions directed at the neck.

\section{Conflict of Interest}

No conflict of interest.

\section{Author Contributions}

NTC: dissection, literature search and manuscript writing; NGS: improvement of the manuscript and editing; STO: manuscript writing and editing; İA: manuscript editing.

\section{Acknowledgements}

We are grateful to all the body donors and their families for their contributions and support in educational and scientific research activities.

\section{References}

1. Karaaslan D, Altinisik U, Peker TT, Nayir E, Ozmen S. External jugular vein catheterization using 'intra-atrial electrocardiogram'. Yonsei Med J 2009;50:222-6.

2. Pangouli E, Tsaraklis A, Gazouli I, Venieratos D. An unusual termination of seven veins in the jugulo-subclavian junction. Int J Morphol 2009;27:1257-60.

3. Arıncı K, Elhan A. Anatomi. 5th ed. Ankara: Güneş Kitapevi; 2005. p.87-9.

4. Nayak BS, Soumya KV. Abnormal formation and communication of external jugular vein. International Journal of Anatomical Variations 2008;1:15-6.

5. Olabu BO, Loyal PK, Matiko BW, Nderitu JM, Misiani MK, Ogeng'o JA. Variant anatomy of the external jugular vein. Anatomy Journal of Africa 2015;4:518-27.

6. Patil J, Kumar N, Swamy RS, D'Souza MR, Guru A, Nayak SB. Absence of retromandibular vein associated with atypical formation of external jugular vein in the parotid region. Anat Cell Biol 2014;47:135-7.

7. Deepak CA, Sarvadnya JJ, Sabitha KS. Variant anatomy of internal jugular vein branching. Ann Maxillofac Surg 2015;5: 284-6.

8. Maneenai N, Arjhansiri K. CT evaluations of anatomical variations of the internal jugular veins in Thai adults. Asian Biomedicine 2013; 7:803-11.

9. Pai M, Vadgaonkar R, Prabhu L, Shetty P. The different termination patterns of the facial vein - a cadaveric study. Firat Medical Journal 2008;13:32-4.

10. Choudhry R, Tuli A, Choudhry S. Facial vein terminating in the external jugular vein. An embryologic interpretation. Surg Radiol Anat 1997;19:73-7.

11. Tubbs S, Shoja MM, Loukas M, (editors). Bergman's comprehensive encyclopedia of human anatomic variation. Hoboken (NJ): Wiley Blackwell; 2016. p. 821-5.

12. Deslaugiers B, Vaysse P, Combes JM, Guitard J, Moscovici J, Visentin M, Vardon D, Becue J. Contribution to the study of the tributaries and the termination of the external jugular vein. Surg Radiol Anat 1994;16:173-7.

13. Haas F, Weiglein A. Section two: conventional workhorse flaps. In: Chan FC, Mardini S, editors. Flaps and reconstructive surgery. China: Elsevier, 157-73.

14. Tellez-Hernandez LV, Tibduiza-Rodriguez IA, Ferreira-Arquez H. Unilateral anatomical variation in the venous drainage of face and neck. International Journal of Pharmaceutical Research, 2019;11: 1152-5.

15. Pyrigakis P, Panagouli E, Venieratos D. Anomalous origin and course of the suprascapular artery combined with absence of the 
suprascapular vein: case study and clinical implications. North American Journal of Medical Sciences 2013;5:129-33.

16. Panagouli E, Tsirigoti A, Kotsira G, Demesticha T, Skandalakis P, Troupis T, Filippou D. An unusual bilateral duplication of the suprscapular vein and its relation to the superior transversescapular ligament revealed by Anatomage Table. Acta Med Acad 2019;48: 307-11.

17. Gupta V, Tuli A, Choudhry R, Agarwal S. Facial vein draining into external jugular vein in humans: its variations, phylogenetic retention and clinical relevance. Surg Radiol Anat 2003;25:36-41.

18. Krmpotic-Nemanic J, Draf W, Helms J. 1988. Surgical anatomy of head and neck. Berlin: Springer-Verlag.

19. Ghosh S, Mandal L, Roy S, Bandyopadhyay. Two rare anatomical variations of external jugular vein - an embryological overview. International Journal of Morphology 2012;30:821-4.

20. Mehra S, Kaul JM, Das S. Unusual venous drainage pattern of face: a case report. J Anat Soc India 2003;52:64-5.

ORCID ID:

N. Tuncel Çini 0000-0003-1412-2634;

N. Güner Sak 0000-0002-3172-1746;

S. Turan Özdemir0000-0002-0407-3608:

I. Arl 0000-0001-7775-9881

deomed.
21. Gupta N, Jain P, Anshu A, Samta. An undivided retromandibular vein receiving facial and posterior auricular vein: case report and clinical repercussion. Indian Journal of Basic and Applied Medical Research 2013;7:710-15.

22. Vani PC, Rajasekhar SSSN, Gladwin V. Unusual and multiple variations of head and neck veins: a case report. Surg Radiol Anat 2019; 41:535-38.

23. Gupta V, Tuli A, Choudhary R, Agarwal S, Mangal A. Facial vein draining into external jugular vein in humans: its variations, phylogenetic retention and clinical relevance. Surg Radiol Anat 2003;25: 36-41.

24. Gogolev MP. The treatment of hydrocephalus by ventriculojugular shunting. Zhurnal Voprosy Neirokhirurgii Imeni N.N. Burdenko 1993;3:24-6.

25. Sabharwal P, Mukherjee D. Autogenous common facial vein or external jugular vein patch for carotid endarterectomy. Cardiovasc Surg 1998;6:594-97.

Correspondence to: Nilgün Tuncel Çini, PhD

Department of Anatomy, School of Medicine,

Uludağ University, Bursa, Turkey

Phone: +90 05534702333

e-mail: nntuncel@gmail.com

Conflict of interest statement: No conflicts declared.

This is an open access article distributed under the terms of the Creative Commons Attribution-NonCommercial-NoDerivs 4.0 Unported (CC BY-NCND4.0) Licence (http://creativecommons.org/licenses/by-nc-nd/4.0/) which permits unrestricted noncommercial use, distribution, and reproduction in any medium, provided the original work is properly cited. How to cite this article: Tuncel Çini N, Güner Sak N, Turan Özdemir S, Arı İ. Multiple variations of superficial and deep veins in the neck region of a cadaver: a case report. Anatomy 2020;14(2):150-155. 